\title{
The transformations of the "Do-It-Yourself" culture and the context provided by digital manufacturing in furniture design
}

\section{SIGRADI2018 TECHNOPOLITICAS \\ xxii congresso da sociedade iberoamericana de gráfica digital 22th conference of the iberoamerican society of digital graphics 07|08|09|novembro|2018 iau usp | são carlos | sp br}

\author{
Amanda Aline Alves de Oliveira \\ FAU-USP | Brazil | amandaaline212@usp.br
}

Tatiana Sakurai

FAU-USP | Brazil | tsakurai@usp.br

\begin{abstract}
This article seeks to deal with the evolution of the DIY culture during its most important periods for the history of furniture and confers great importance to the present reality that provides the constitution of these artifacts through digital manufacturing. Thus, issues such as the quality of what has been produced and even the relevance of design professionals of the culture of making in the digital era are treated.
\end{abstract}

Keywords: DIY; Digital fabrication; Furniture; Fab Labs Livres SP.

\section{INTRODUÇÃO}

Este artigo tem por objetivo principal refletir sobre a produção de peças de mobiliário na era digital, dentro da cultura "Do-It-Yourself", em especial aquelas geradas no contexto da rede Fab Lab Livre SP. Para aferir a qualidade projetual desta produção, realiza-se, de forma qualitativa, uma leitura que se utiliza de múltiplas técnicas de coleta de dados (Creswell, 2010).

Por meio de revisão bibliográfica, de títulos nacionais e internacionais em língua inglesa, buscou-se compreender historicamente a origem e evolução do DIY. A pesquisa iconográfica, obtida por meio de busca em fontes secundárias e levantamento de campo na cidade de São Paulo, permitiu realizar análises projetuais nos contextos explorados. E por fim, entrevistas semi-estruturadas com especialistas; projetistas de peças de mobiliário com fabricação digital e funcionários da rede Fab Lab Livre.

\section{CULTURA DIY PRÉ-DIGITAL}

Desde a primeira vez que a expressão Do-lt-Yourself apareceu na revista americana Suburban Life em 1912 (Harris, 2012), observa-se um crescente interesse sobre como co-criar artefatos e materializar objetos com as próprias mãos. Os resultados destas criações refletem e registram tendências e estilos de vida que tendem a variar segundo os contextos econômicos, políticos e sociais das quais emergem.

Em sua fase inicial, segundo Harris (2012), a revista Suburban Life tinha o objetivo de fornecer conteúdo para principiantes e era constituída por uma sucessão de casos de pessoas comuns que realizavam tarefas típicas de profissionais ligados à marcenaria e à construção, com as chamadas: Como eu construo a minha casa, Como decorar e Algumas coisas que mamãe costumava fazer.

É importante destacar que o contexto determinado pelas guerras (1914-1945), propiciou uma forte adesão à prática do "Faça-você-mesmo". Com uma abordagem pragmática e utilitarista nesse início, objetos cotidianos eram feitos a partir de recursos restritos. O afastamento dos homens dos lares resultou na ênfase da participação feminina para a realização de atividades corriqueiras. Os móveis, devido à limitação de recursos e da mão-de-obra especializada, eram objeto também dessa prática.

Desta forma, podemos compreender o DIY na vida das pessoas como um correspondente de suas necessidades, visto que, ele se adapta às circunstâncias das quais se origina. Um design notável que reflete as condições limitantes do período foi o Crate furniture, móveis desenvolvidos por Gerrit Rietveld a partir de engradados de madeira (Fineder, Geisler e Hackenschmidt, 2016). É um exemplo menos conhecido do que a sua cadeira ícone do movimento De Stijl, porém, é um mobiliário que apresenta preocupações com relação à ergonomia, estética, facilidade de encontrar a matéria prima necessária para sua confecção, baixa complexidade de execução e custo reduzido.

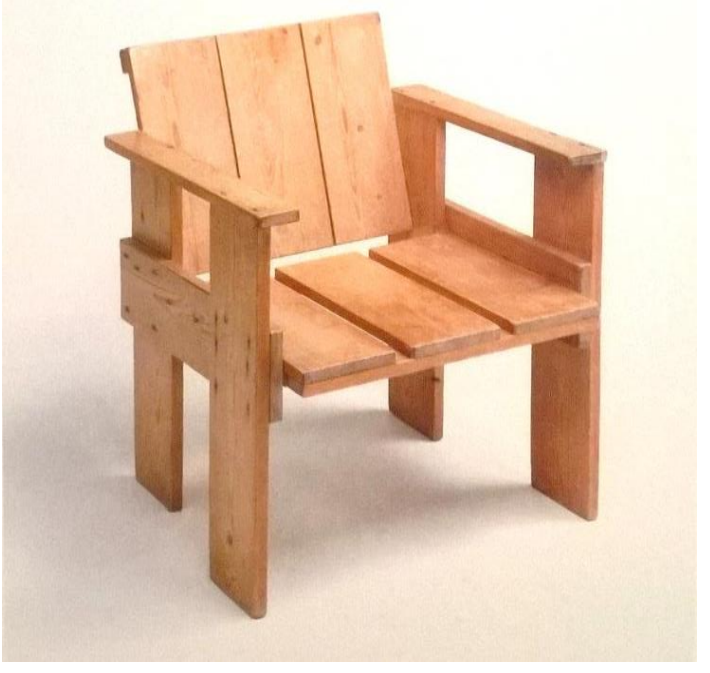

Figura 1: Poltrona da série Crate furniture de Gerrit Rietveld, 1934. Fonte: Fineder, Geisler e Hackenschmidt (2016) 
Fineder, Geisler e Hackenschmidt (2016) apontam outro exemplo que reflete as contingências daquela época: os móveis do arquiteto e designer alemão Ferdinand Kramer conhecidos como Knock-Down. Pela sua simplicidade e características de fácil montagem e desmontagem, refletem o estado de mobilidade das pessoas, como a mesa Charlotte, replicada até os dias hoje em guias de DIY e mobiliário nômade.

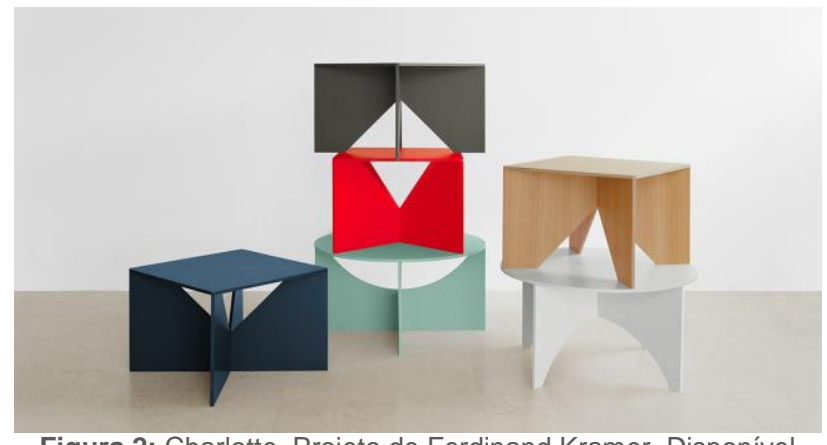

Figura 2: Charlotte. Projeto de Ferdinand Kramer. Disponível em: <https://www.e15.com/en/charlotte.html>

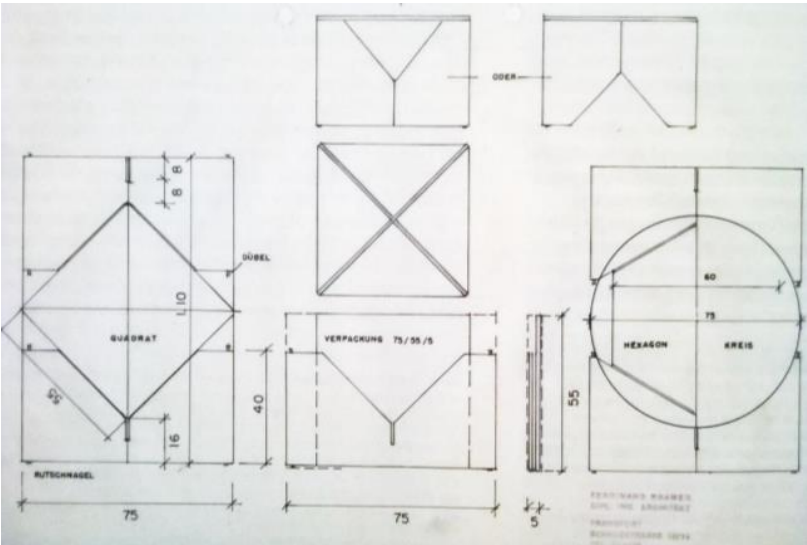

Figura 3: Desenho técnico com a montagem da mesa Charlotte de Ferdinand Kramer. Fonte: Fineder, Geisler e Hackenschmidt (2016)

Pelas imagens 2 e 3 nota-se que estes móveis pertencem a um design em transformação. Ou seja, trata-se de uma mudança de concepção de interiores "carregados" para interiores "leves" de móveis com desenho simples obtido a partir de formas puras. No entanto, na década de 1950 do pós-guerra houve um novo momento da cultura do "Faça-Você-Mesmo", com a perspectiva coletiva de criar uma realidade melhor e também voltada para atender as necessidades do baby boom. Com a crescente popularização de revistas e manuais com instruções de montagem para todos os tipos de objetos do cotidiano, o "Faça-Você-Mesmo" deixa de ter um caráter de necessidade, para passar a ter um caráter de recreação (Fineder, Geisler e Hackenschmidt, 2016). Aqui o Do-ltYourself teve um papel chave ao se tornar instrumento para a criação de uma nova realidade, considerando a capacidade de criação das pessoas em torno desta reconstrução.

A exposição no MOMA e a publicação do livro em 1964, do arquiteto Bernard Rudofsky: Architecture without architects: a short introduction to non-pedigreed architecture são, sem dúvida, uma mudança de paradigma para as esferas da arquitetura que impactou também ao design. Visto que esta tomada de iniciativa e manifestação de processos populares de construção por pessoas não especialistas na área também é necessária aos processos DIY. Na década de 1970 um fator que coloca a cultura DIY em evidência é a recessão econômica, segundo James Hennessey em Fineder, Geisler e Hackenschmidt (2016): "DIY parece seguir tendências da economia e renda. Durante a década de 1970, quando as rendas eram baixas, as pessoas eram atraídas pelo DIY" (p.8, tradução nossa).

O DIY assume uma nova faceta, a estética da resistência, cuja finalidade era a democratização do consumo em meio aos movimentos anti-capitalistas e anti-imperialistas, ou seja, o movimento de contracultura refletia-se também no design e na arquitetura. O movimento do "Faça-VocêMesmo" tornou-se um instrumento de luta contra o consumismo e a construção das próprias casas e móveis pelas pessoas eram um símbolo de aderência ao movimento. Além da busca de outro estilo de vida inspirado pelos hippies que representavam o auge do movimento de contracultura.

Exemplos de como ocorrem estas transições da vida cotidiana para a materialidade no design ou na arquitetura puderam ser expostas nos livros Nomadic furniture volumes 1 e 2 dos autores James Hennessey e Victor Papanek escritos respectivamente em 1973 e 1974. Estes livros foram publicados com a finalidade de se tornarem catálogos de móveis de fácil montagem e desmontagem ou disponíveis para compra na época ou com sugestões para que os próprios leitores criassem seus móveis a partir das soluções projetuais trazidas pelos volumes.

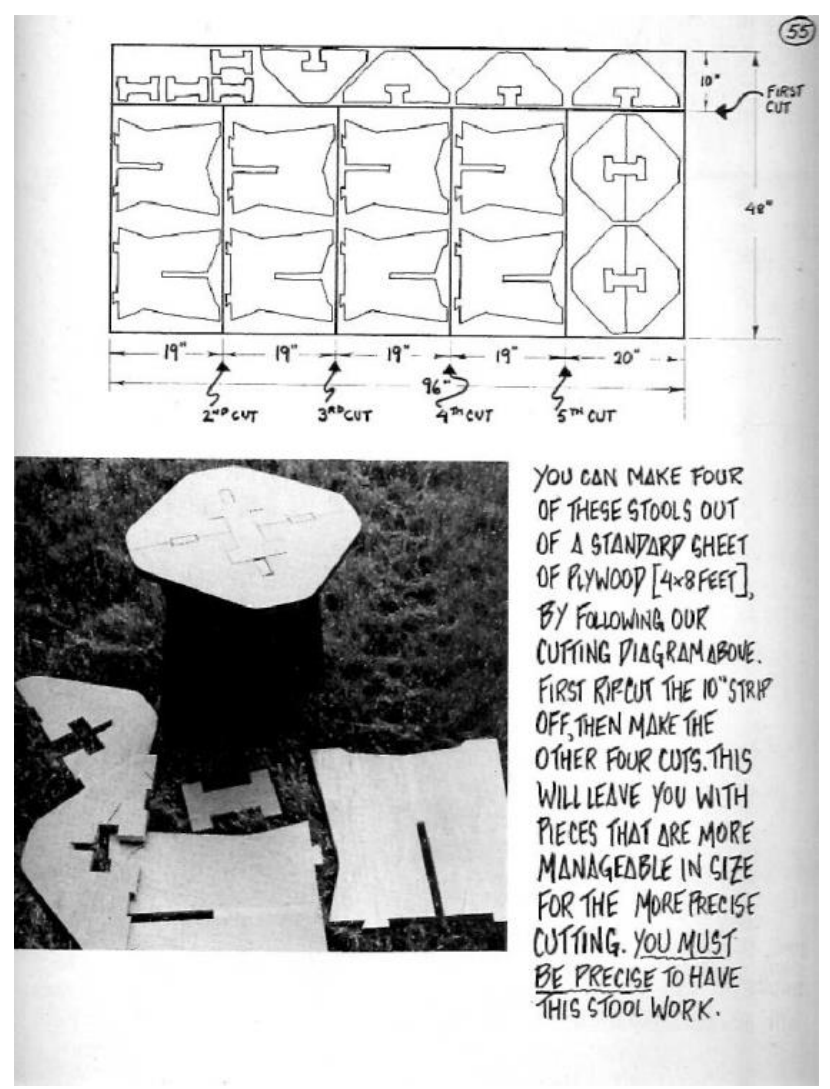

Figura 4: Excerto do livro Nomadic Furniture - volume 1, com imagens e textos. Fonte: Papanek e Hennessey (1973)

Outo fator que coloca a cultura DIY em evidência na década de 1970 é a recessão econômica mundial 
causada pela crise do petróleo nos Estados Unidos. O Do-lt-Yourself ganha maior relevância durante os contextos de retração financeira, e também, neste período, há o aparecimento das primeiras preocupações ambientais. As pessoas passam a se questionar sobre a necessidade de adquirir novos bens de consumo.

Observa-se, por exemplo, o crescimento da utilização de materiais reutilizados, sendo que o seu uso também era encarado como uma forma de estimular a inventividade no processo criativo. Houve a consolidação da tendência em instigar as pessoas a co-criarem, ou seja, de possuírem uma atitude ativa frente ao projeto e de intervirem sobre ele para criarem algo que Ihes se já próprio. Como bem "alertam" os autores Papanek e Hennessey (1974): "Lembre-se: você não está lendo um livro sobre design. Pelo contrário, este é um livro para desmitificar o design e torná-lo disponível para as pessoas." (p.3, tradução nossa).
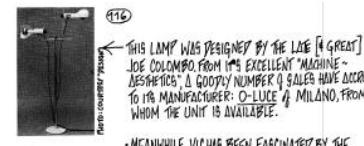

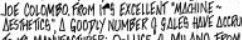

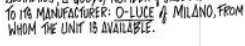

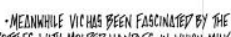

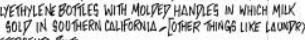
PEIERGENTS, Riótio GEMIALS ER, $\triangle 15$

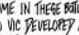
LOMP, WHIOO WE EEEL

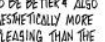
- UUE ORIGASLLL.FE

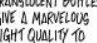
LGHT QuaLIYY 00
THESE RECTLED MILK ROTHES.

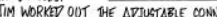

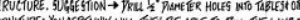

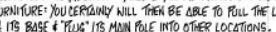

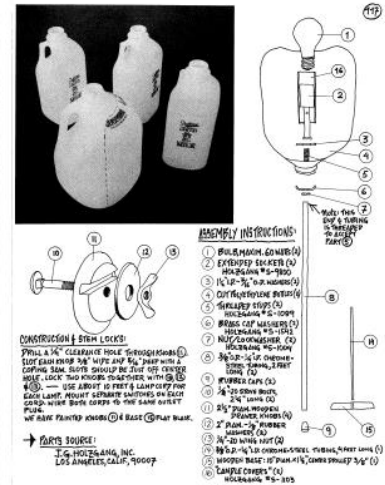

Figuras 5 e 6: Excertos do livro Nomadic Furniture - volume 1, com imagens e textos. Fonte: Papanek e Hennessey (1973)

Porém, apesar de todas as conquistas para a cultura DIY que estes anos propiciaram, Fineder, Geisler e Hackenschmidt (2016) observam: "(...) a partir do final dos anos 1980, as publicações DIY relevantes tornaramse cada vez mais convencionais e comerciais (...)" (p.92, tradução nossa). Apontam também para uma perspectiva de musealização de móveis ícones da cultura DIY: “(...) móveis DIY, no entanto, têm certo charme - pelo menos em alguns círculos - que se baseia no fato de que os objetos em questão estão tentando escapar dos parâmetros reinantes da sociedade de consumo e do rótulo de fetichismo." (p.117, tradução nossa). Inclusive o próprio livro Nomadic Furniture 3.0 apresenta vários móveis projetados por designers reconhecidos como Ferdinand Kramer, Enzo Mari, Gerrit Rietveld, Ken Isaacs, James Hennessey e Victor Papanek. Se na época em que foram lançados eram considerados quase como um anti-design por sua simplicidade e caráter de improvisação, hoje, estes mesmos mobiliários se tornaram ícones, com apelo forte comercial, da cultura Do-It-Yourself.

A partir desta época a cultura DIY sofreu outra grande revolução com a entrada do computador de uso doméstico em casa, conectado às redes de comunicação, que possibilitou o download de projetos, eliminou custos de publicação e potencializou a sua difusão. Outra realidade que também faz parte deste mundo virtual são os fóruns de discussão que também permitem visualizar de maneira imediata a aceitação ou rejeição do público sobre as postagens e, em contrapartida, permite que pessoas que não tenham formação específica na área postem seus projetos.

\section{A CULTURA DIY A PARTIR DA PERSPECTIVA DA FABRICAÇÃO DIGITAL}

O acesso a este conteúdo de uma cultura impressa para a cultura digital chamada, "sociedade em rede" (Castells, 2005), possibilitou novas conquistas para a cultura DIY. Com transformações velozes, qualquer pessoa está apta a se tornar protagonista desta nova história do "FaçaVocê-Mesmo", potencializada com a introdução dos fab labs que permitem a aprendizagem através de experiências vivenciadas na prática. Os Fab Labs Livres SP da Prefeitura Municipal de São Paulo proporcionam um caso muito especial de fabricação digital, porque segundo Fonseca de Campos, Dias (2018): "Desde 2016, a cidade de São Paulo conta com a maior rede pública de laboratórios de fabricação digital do mundo: a rede municipal Fab Lab Livre SP" (p. 42). Tendo como um dos objetivos da rede garantir a autonomia intelectual da população frente a esta tecnologia.

Em entrevista concedida para a autora principal deste artigo, o coordenador da rede Fab Lab Livre SP, Ricardo Elias Delgado, posicionou-se com a seguinte resposta para a pergunta: Você acha que a missão pela qual os Fab Labs Livres foram criados está sendo cumprida?

Eu acredito que sim. Acredito que de dois anos atrás, por exemplo, quando o fab lab estava bem no começo, pouquíssimas pessoas tinham conhecimento sobre o que era. Poucos imaginavam que poderiam usar uma impressora 3D ou uma máquina de corte a laser. E aí nós temos espaços na periferia de São Paulo como em Cidades Tiradentes, por exemplo, com uma turma de jovens que saem da escola e praticamente batem cartão todo dia no fab lab. Todo dia estão lá participando das atividades ou tentando propor alguma coisa nova, então isto mostra que está sendo cumprido. É uma coisa bem interessante.

Cada unidade da rede Fab Lab Livre SP pode proporcionar uma experiência única de conhecimento devido à diversidade de pessoas que procuram aqueles espaços e até mesmo as habilidades de seus instrutores. Qualquer fab lab é constituído por um conjunto de máquinas, mas as pessoas que operam por meio destes recursos é que conferem a identidade característica de cada espaço. Dentro dos fab labs ocorre dois termos importantes da cultura DIY que se referem às circunstâncias de projeto, Neves (2014) apresenta o "DIY (Do-It-Yourself - Faça-Você-Mesmo)" e o "DIWO - (Do-ItWith-Others - faça com os outros)" (p.184). Este último é um termo não tão difundido, mas que define bem o espírito presente nos fab labs, visto que segundo Neves (2014) há uma clareza de que: "Educação dentro de Fab Lab é algo tratado com a mesma estratégia das outras áreas: horizontalmente e baseado no conceito de "hands on" (mão na massa). (...) A figura do professor não existe, mas sim a de Gurus que auxiliam os alunos a atingir suas metas e a compreender esta nova forma de educação." (p.149).

Com esta quebra dos padrões tradicionais de aprendizagem, estamos diante de um profícuo ambiente para inovações, mas para Smith et al. (2017): “(...) a questão é: o movimento do workshop pode ir além de sua 
demonstração de possibilidades de prototipagem e envolver-se em processos de catalisação de profunda transformações?" (p.120, tradução nossa). Ou seja, o que está de fato em jogo não é o uso da fabricação digital em si, mas as transformações sociais que elas podem ocasionar.

Os fab labs também devem ser analisados não somente sob a olhar restrito da produção de objetos, mas também, sobre suas capacidades de gerar interferências com o mundo virtual e com a realidade que os cerca. Para Bonsiepe (2015), "O conceito central de design não seria mais a forma, mas o espaço de ação que é aberto por meio de um artefato" (p. 7, tradução nossa).

Alguns pensamentos mais radicais sobre o avanço destas tecnologias são expostos por Johan Soderberg (2013) como uma oportunidade real para se chegar ao fim da sociedade de consumo: "Para os mais radicais, a reapropriação das ferramentas pela população abriria caminho para uma 'democratização' da produção industrial, tendo em mira a abolição da sociedade de consumo".

Porém, como sinaliza Fonseca de Campos, Dias (2018), esta apropriação do maquinário pela população só ocorrerá como instrumento de emancipação social quando vier acompanhada de iniciativas sociais aliadas ao uso das máquinas e não apenas como instrumento de reforçar relações verticais de poder, que sempre existiram. Dados importantes de serem destacados sobre a rede municipal Fab Lab Livre SP é que (Fonseca de Campos, Dias): "até o final de 2017, mais de 70 mil usuários já haviam frequentado os laboratórios, e mais de 1.000 projetos já tinham sido inscritos" (2018, p. 43). Ou seja, o que estes dados revelam é que a população está se apropriando de maneira efetiva desta tecnologia e a direcionando para o atendimento de suas necessidades como foi destacada a importância neste estudo através dos autores citados.

É criada uma expectativa em relação aos fab labs destes criarem uma espécie de renovação da cultura prosumer (termo utilizado pelo livro Nomadic Furniture 3.0 para designar as pessoas que são produtoras e consumidoras finais de seus produtos). O que ocorre na prática é que estas pessoas não precisam ser, necessariamente, designers para produzirem seus objetos.

A partir de Soderberg (2013) podemos compreender que estas novas circunstâncias de produção que envolvem a fabricação digital fazem parte de um movimento de resistência contra antigos padrões ao citar que: "Os makers não são herdeiros do movimento operário - são antes o resultado histórico da negação desse movimento.".

Outra consequência desta renovação industrial pautada em máquinas poderia ser o desemprego, mas esta preocupação para Castells (2005) não é justificável pois, as revoluções tecnológicas não implicam em demissões, porque embora as máquinas reduzam a quantidade de horas trabalhadas, elas elevam a competitividade do empregador o que, por consequência, aumenta a quantidade de vagas necessárias para atender as novas solicitações do produto. Outra consequência importante de uma produção em larga escala em uma indústria que deixa de ser produzida ao repetir sempre os mesmos padrões, para poder ser feitas de maneira personalizada é que Ratto e Ree (2012) chamam de customização em massa. A mesma pessoa que faz o design do artefato, pode escolher os materiais, organizar a forma como ele será produzido e ser também o usuário final do produto obtido. Essa possibilidade é real devido aos projetos serem armazenados nos bancos de dados disponíveis para tecnologias digitais, ou modelos open source, os quais são disponibilizados de forma que possam sofrer alterações.

Outro aspecto desta renovação é que todas estas características de customização vivenciadas no cotidiano das práticas DIY leva a história do design a um ponto de inflexão, pois, os prosumers são vistos como "sabotadores" da profissão do designer, visto que, a princípio, caso todos são capazes de produzir artefatos a figura do desenhista industrial se torna dispensável. No entanto, é cada vez mais necessária a presença de bons designers para fomentar boas práticas de "Faça-VocêMesmo".

Gui Bonsiepe (2015) tem um olhar apreensivo sobre a produção massiva de objetos desenvolvidos por esta cultura prosumer. "Resta saber se, com esse método de design e produção, a atividade de design se tornará popular e quais produtos serão fabricados. Nós não podemos excluir a possibilidade de acabar em uma fabricação maciça de bibelôs" (p. 7, tradução nossa).

Uma reflexão importante para se destacar no contexto atual de produção dos fab labs é sobre o princípio da sustentabilidade. O que deve ser obeservado neste cenário é que os fab labs também usam como principio gerador de objetos a transformação de matérias-primas. Uma atitude compensatória para minimizar a geração de resíduos é o desenvolvimento de oficinas que envolvem as sobras destes materiais. Segundo Kohtala (2016), "O fab lab não se tornaria uma fábrica para meros brinquedos e hobbies, mas sim brinquedos e hobbies - e ferramentas - para criar e compartilhar conhecimento e, esperava-se, inventividade colaborativa" (p. 14, tradução nossa). O professor do Garagem Fab Lab e do OficinaLab em São Paulo, que também dá aulas de marcenaria, Roberto Stelzer, em entrevista à autora principal, deu a seguinte resposta ao se referir ao exemplo da cadeira abaixo:

O desenho ficou facilitado, tem uma estética bacana, mas é um móvel que é pesado pra caramba. Tanto que depois dessas eu nunca mais vi ninguém fazendo estes projetos. As pessoas preferem projetos mais leves, mas de cara quem desenhou isto daí achou que era uma coisa super bacana. E é né, porque ... é meio evolução. Então, é melhor alguém desenhar uma coisa um pouquinho fora e depois ir acertando, do que não desenhar nada. 


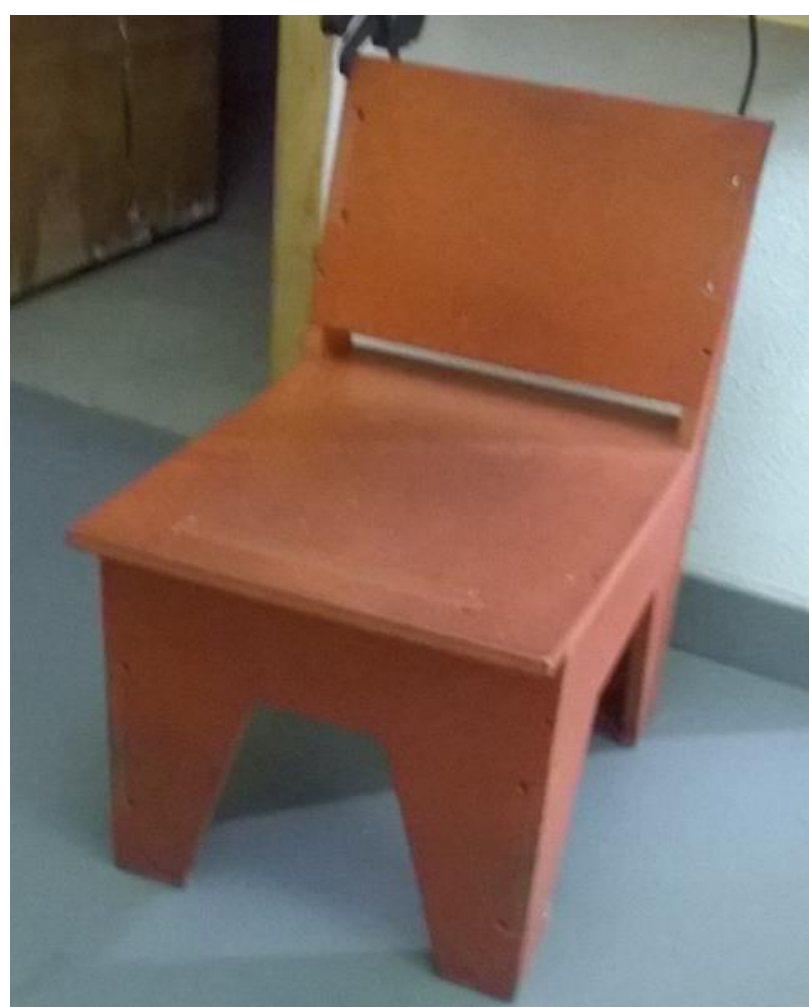

Figura 7: Cadeira catalogada no Garagem Fab Lab. Fonte: Autora (2017)

Quando foi realizada a pergunta sobre qual é a maior vantagem de se produzir móveis com fabricação digital para o idealizador do Jangada Fabricação Digital, Rafael Cordeiro, em Belo Horizonte, que é uma iniciativa particular para o desenvolvimento de mobiliário, a partir de fabricação digital se obteve a seguinte resposta:

A maior vantagem seria no caso de formas orgânicas e complexas, volumetrias e encaixes, que nos possibilita obter resultados rápidos de alta qualidade, com repetitividade, o que normalmente não se consegue por meio de marcenaria tradicional. Para cortes retos, por exemplo, você pode comprar das madeireiras a chapa já cortada, além do que, o corte reto é barato, o que pode não justificar muito fazer na CNC. Então penso que a maior vantagem seria para formas mais orgânicas e peças mais complexas, com encaixes.

No entanto, o que se pode constatar é o emprego de desenhos característicos da marcenaria tradicional sendo replicados na marcenaria digital. Desenhos pautados em cortes retos ainda dominam o cenário. Há um potencial inexplorado no uso destas máquinas.

Diante destas informações temos também que manter um olhar cuidadoso sobre a produção de móveis dentro destes laboratórios que servem ao intuito de serem objetos de aprendizagem sobre o funcionamento destas máquinas e os que são feitos com um propósito diferente e com a intenção de serem considerados objetos de design.

O que Rafael Cardoso na introdução do Livro "O mundo codificado" de Flusser (2007) nos diz é que: “(...) o resultado final de toda nossa manipulação de palavras, imagens, artefatos é um imenso acúmulo de lixo, mesmo que eletrônico" (p.15). O que o pensamento de Rafael Cardoso revela é que toda essa produção é pautada nas interferências do homem para a criação de um mundo artificial, do qual, ele mesmo se escraviza para manter. $\mathrm{E}$ Flusser (2007) faz afirmações com relação aos programados e aos programadores: "Não: a sociedade do futuro, imaterial, será uma sociedade sem classes, uma sociedade de programados programadores. Essa é, portanto, a liberdade de decisão que nos é aberta pela emancipação do trabalho. Totalitarismo programado" (p.64). Assim, abre perspectivas que estimulam o pensamento de que inclusive as liberdades de escolha são pré-determinadas. É possível compreender que algo bem discreto e similar ocorre com a fabricação digital ao se compartilhar um código. O que ocorre quando fazemos isto é criar um poder de interferência no projeto limitada dentro dos limites da programação. É possível escolher entre diversas especificações já pré-estabelecidas no momento da customização. Assim, podemos ter uma visão das limitações da tecnologia como um universo programado, mas seria este um totalitarismo? Então, seria a aposta dos fab labs como espaços onde se pode criar quase qualquer coisa um engano? Do ponto de vista de Flusser é provável que sim, mas sob o ponto de vista dos fab labs, há sim a possibilidade de se criar quase qualquer coisa, porém, dentro dos limites do que já foi programado.

Uma aproximação alternativa entre a produção de objetos e os fab labs é proveniente das instituições de ensino, em que a materialização de objetos visa um fim específico e não apenas a constante descoberta das inúmeras possibilidades de projeto viáveis por esta tecnologia.

Importantes parcerias entre as instituições e os Fab Labs Livres SP poderiam ser feitas para ajudar a desenvolver metodologias para as oficinas propostas por estas unidades, as quais se desenvolvam projetos com um teor crítico mais consolidado. $\mathrm{E}$, neste caso, não se trata de uma imposição do que é certo ou errado por parte das universidades, mas de fato, uma parceria.

Como se sabe, uma das propostas dos Fab Labs Livres SP é permitir com que as pessoas tenham acesso a esta tecnologia, que em condições normais, não teriam. Mas sendo possível esta aproximação, por qual motivo não tentar?

\section{CONCLUSÕES}

Foi possível identificar três momentos que propiciaram os auges da cultura Do-It-Yourself: provocados pelo pósguerra, a contracultura das décadas de 1960 e 1970 e a era digital, assim, podemos compreender que a cultura DIY é uma expressão na contemporaneidade da vida, do trabalho, do design e da cultura, além do avanço dos métodos de produção.

Outros aspectos analisados são a capacidade destes fab labs serem apropriados pelas pessoas dos locais dos quais estão inseridos para provocar mudanças positivas na vida de seus frequentadores.

Com isto, espera-se que este artigo possa servir como um instrumento para se pensar sobre a trajetória da produção destes fab labs, que por um lado, no panorama brasileiro, faz parte de uma realidade recente, mas que já conta com uma proposta inovadora, possibilitada pelos Fab Labs Livres SP. E também a responsabilidade ambiental que toda forma de produção, assim como os 
fab labs devem ter. Uma contribuição importante presente nestas reflexões e que pode impactar a produção de móveis obtidos a partir de fabricação digital no presente é referente ao design do que vem sendo produzido. No caso específico do mobiliário também é muito recorrente visualizar tecnologias digitais sendo utilizadas para criação de móveis característicos de uma marcenaria tradicional.

Assim, foi possível abrir espaço para o questionamento sobre a pertinência ou não deste universo da fabricação digital se restringir apenas aos profissionais com formação específica na área de projeto. Visto que, na cultura impressa, as publicações de DIY passavam por uma espécie de "filtro" do que iria ser publicado, porém, hoje, com as publicações de projetos em modelos open source, qualquer um está apto a exercer tal tarefa.

Outra grande preocupação levantada por este estudo é sobre a possibilidade de musealização dos móveis que foram criados com o intuito de serem objetos destinados à cultura "Faça-Você-Mesmo" ao se tornarem móveis ícones do design. Caso isto aconteça, eles estariam servindo ao propósito contrário de seus idealizadores ao criarem móveis acessíveis e de fácil execução para servir as pessoas em seus usos cotidianos.

\section{AGRADECIMENTOS}

Ao Programa de Pós-Graduação em Arquitetura e Urbanismo da FAUUSP.

Ao CNPQ - Conselho Nacional de Desenvolvimento Científico e Tecnológico, pelo apoio que viabilizou a pesquisa de mestrado que originou este artigo.

Aos entrevistados.

\section{REFERÊNCIAS}

Bonsiepe, G. (2015). Desobediencia proyectual. Conferência para o simpósio "Can design change society?". Berlim.

Castells, M. (2005). A sociedade em rede. São Paulo: Paz e Terra.
Creswell, J. M. (2010). Projeto de pesquisa: métodos qualitativo, quantitativo e misto. Porto Alegre: Artmed.

Fineder, M., Geisler, T., Hackenschmidt, S. (2016). Nomadic Furniture 3.0: New Liberated Living? Viena: Mak Studies.

Flusser, Vilém. (2007). O mundo codificado. São Paulo: Ubu editora.

Fonseca de Campos, P. E. F., Dias, H. J. S. (2018, maio). A insustentável neutralidade da tecnologia: o dilema do Movimento Maker e dos Fab Labs. Liinc em Revista, (14), 33-46. doi: https://doi.org/10.18617/liinc.v14i1.4152

Harris, R. (2012). Building a market. The rise of the home improvement industry, 1914-1960. Chicago: The University of Chicago Press.

Isaacs, K. (1974). How To Build Your Own Living Structures. New York: Harmony Books.

Kohtala, C. (2016). Making 'making' critical: How sustentability is constituted in Fab Lab ideology. In: Kohtala, C. Making sustainability: How Fab Labs Address Environmental Issues. Helsinki: Aalto ARTS Books.

Neves, H. (2014). Maker Innovation. Do open design e Fab Labs...às estratégias inspiradas no movimento maker. Retrieved from http://www.teses.usp.br/teses/disponiveis/16/16134/tde14072015-112909/pt-br.php

Papanek, V., Hennessey, J. (1973). Nomadic Furniture. New York, Toronto: Pantheon Books.

Papanek, V., Hennessey, J. (1974). Nomadic Furniture 2. New York, Toronto: Pantheon Books.

Ratto, M., Ree, R. (2012). Materializing information: 3D printing and social change. First Monday, Chicago, 17. Retrieved from:

http://firstmonday.org/ojs/index.php/fm/article/view/3968/3273

Smith et al. (2017). Grassroots innovation movements: pathways to sustainability. New York: Routledge.

Soderberg, J. (2013). A ilusória emancipação por meio da tecnologia: Impressoras 3D, a última solução mágica. Le monde diplomatique, 66. Retrieved from: http://diplomatique.org.br/a-ilusoria-emancipacao-por-meioda-tecnologia/ 